\title{
O estresse emocional em gestantes no contexto da pandemia do Covid-19
}

\author{
Emotional stress in pregnant women in the context of the Covid-19 pandemic \\ Estrés emocional em mujeres embarazadas en el contexto de la pandemia
}

Recebido: 28/10/2021 | Revisado: 06/11/2021 | Aceito: 10/11/2021 | Publicado: 17/11/2021

Kassandra de Oliveira Queiroz

ORCID: https://orcid.org/0000-0001-8183-491X Universidade Paulista, Brasil

E-mail: kovqueiroz@gmail.com

Maria Luiza Rêgo Bezerra

ORCID: https://orcid.org/0000-0002-3336-7760 Universidade Paulista, Brasil

E-mail: maria.bezerra@docente.unip.br

\begin{abstract}
Resumo
O objetivo deste estudo foi analisar as situações causadas pela pandemia pela COVID-19 que agravaram o estresse emocional nas gestantes e como a equipe de Enfermagem prestará assistência diante as mesmas. Trata-se de uma revisão integrativa de literatura, através da pergunta norteadora: "Como a equipe de Enfermagem desenvolve as ações de cuidado para tentar diminuir o estresse emocional nas gestantes no decurso do ciclo gravídico durante a pandemia?", elaborada a partir do método PICO, em três bases de dados com os descritores gestantes, saúde mental, enfermagem obstétrica e adaptação. Foram incluídos dezesseis artigos, doze sendo nacionais, quatro em inglês e zero em espanhol, com anos de publicação de 2018 a 2021. A Enfermagem desenvolverá a assistência por meio da telenfermagem, compactando o pré-natal nas consultas virtuais e as visitando apenas quando necessário e trajando a paramentação obrigatória, prevendo a segurança da gestante e o menor tempo de contato físico possível à fim de evitar a possibilidade de transmissão da COVID-19. Os profissionais poderão utilizar a Fear Scale for the Perinatal Period para avaliar o medo das gestantes referente ao COVID-19 para que possam, de forma precisa, orientar, acolher e encaminhar a mulher no com o estresse emocional agravado período gravídico. Portanto, as gestantes podem se tranquilizar diante de seus medos, pois a equipe de Enfermagem se faz presente e preparada para lidar com as divergências em conjunto com as mesmas.
\end{abstract}

Palavras-chave: Gestantes; Saúde mental; COVID-19; Enfermagem obstétrica; Adaptação.

\begin{abstract}
The aim of this study was to analyze the situations caused by the COVID-19 pandemic that aggravated emotional stress in pregnant women and how the Nursing team will provide assistance in these situations. This is an integrative literature review, through the guiding question: "How does the Nursing team develop care actions to try to reduce emotional stress in pregnant women during the pregnancy cycle during the pandemic?", elaborated based on the method PICO, in three databases with the descriptors pregnant women, mental health, obstetric nursing and adaptation. Sixteen articles were included, twelve being national, four in English and zero in Spanish, with years of publication from 2018 to 2021. Nursing will develop care through telenursing, compressing prenatal care in virtual consultations and visiting them only when necessary and wearing mandatory attire, providing for the safety of the pregnant woman and the shortest possible physical contact time in order to avoid the possibility of transmission of COVID-19. Professionals will be able to use the Fear Scale for the Perinatal Period to assess the fear of pregnant women regarding COVID-19 so that they can accurately guide, welcome and refer the woman in the pregnancy period with aggravated emotional stress. Therefore, pregnant women can be calm in the face of their fears, as the Nursing team is present and prepared to deal with differences together with them.
\end{abstract}

Keywords: Pregnant women; Mental health; COVID-19; Obstetric nursing; Adaptation.

\section{Resumen}

El objetivo de este estudio fue analizar las situaciones provocadas por la pandemia COVID-19 que agravaron el estrés emocional en gestantes y cómo el equipo de Enfermería brindará asistencia en estas situaciones. Se trata de una revisión integradora de la literatura, a través de la pregunta orientadora: “¿Cómo el equipo de Enfermería desarrolla acciones de cuidado para tratar de reducir el estrés emocional en gestantes durante el ciclo de gestación durante la pandemia?", Elaborado con base en el método PICO, en tres bases de datos. con los descriptores gestante, salud mental, enfermería obstétrica y adaptación. Se incluyeron dieciséis artículos, doce nacionales, cuatro en inglés y cero en español, con años de publicación del 2018 al 2021. La enfermería desarrollará la atención a través de la teleenfermería, comprimiendo la atención prenatal en consultas virtuales y visitándolas solo cuando sea necesario y con vestimenta obligatoria. 
proporcionando la seguridad de la mujer embarazada y el menor tiempo posible de contacto físico para evitar la posibilidad de transmisión del COVID-19. Los profesionales podrán utilizar la Escala de Miedo del Periodo Perinatal para evaluar el miedo de las embarazadas al COVID-19 para que puedan orientar, acoger y derivar con precisión a la mujer en el periodo de embarazo con estrés emocional agravado. Por tanto, las embarazadas pueden estar tranquilas ante sus miedos, ya que el equipo de Enfermería está presente y preparado para afrontar las diferencias junto con ellas.

Palabras clave: Mujeres embarazadas; Salud mental; COVID-19; Enfermería obstétrica; Adaptación.

\section{Introdução}

Em 31 de dezembro de 2019 foi relatado o novo coronavírus (COVID-19) que é causado pelo vírus SARS-CoV-2, e em 30 de janeiro de 2020 a World Health Organization (WHO) declarou que a doença constitui Emergência de Saúde Pública de Importância Internacional (ESPII) e em 11 de março de 2020, o estado de pandemia foi declarado com a COVID-19 afetando 216 países (WHO, 2020). Por dados informados pela WHO, com o relatório formulado em 12 de fevereiro de 2021, o mundo consta um total de 107.423 .526 casos e 2.360 .280 mortes registradas (OPAS/OMS, 2021).

Foram adotadas medidas de proteção contra a COVID-19, como o distanciamento e isolamento social (Brasil, 2020). E o mundo inteiro foi pego desprevenido e encontrou diversas limitações e mudanças repentinas na vivência da população e gerou pânico, principalmente nas gestantes, que pela gestação, já se encontravam imunossuprimidas, gerando um maior estresse emocional somado ao medo e incertezas do futuro e da ciência. (Estrela et al, 2020).

Uma das complicações para as gestantes é o estresse emocional causado pelas transformações físicas e psíquicas que ocorrem durante a gestação, e durante a pandemia os níveis se intensificaram, afetando as expectativas das gestantes, ao desencadear ou acentuar o medo do parto, assim como as práticas de assistência ao mesmo (Souto et al, 2020). E após o parto, as preocupações se tornam presentes nas questões de amamentação, vacinação, estado emocional da puérpera diante ao isolamento social, e cuidados com o bebê, principalmente referindo-se a primigestas.

Diante disso, é fundamental o papel da Enfermagem para orientar, além do que já é preconizado no pré-natal, as gestantes, sobre os mitos à cerca da COVID-19 e ajuda-las a identificar os sintomas de estresse emocional como a sensação de esgotamento físico e mental, sensação de constante cansaço, irritabilidade ou tristeza sem motivos aparentes e sintomas físicos como a dificuldade para dormir, cefaleia, sensação de fadiga, dores nas pernas e taquicardia (Cunha et al, 2020) e se esses sintomas perduram por muito tempo. Por isso é recomendável manter a comunicação com as gestantes, a fim de fornecer informações sobre a quem consultar em caso de emergência, e para consultas virtuais, presenciais ou domiciliares, se necessário (OPAS/OMS, 2020).

Tendo em vista esse cenário, questiona-se: como a equipe de Enfermagem desenvolve as ações de cuidado para tentar diminuir o estresse emocional nas gestantes no decurso do ciclo gravídico durante a pandemia? Por conseguinte, o objetivo deste estudo foi analisar as situações causadas pela pandemia pela COVID-19 que agravaram o estresse emocional nas gestantes e como a equipe de enfermagem prestará assistência diante as mesmas.

\section{Metodologia}

\subsection{Tipo de estudo}

Adotou-se a revisão integrativa da literatura, considerada uma metodologia que integra as evidências científicas ao âmbito da saúde visando, com outros estudos independentes, a compreensão do tema. Por conseguinte, foi determinada, de acordo com as etapas de uma revisão integrativa, a questão norteadora, os critérios de inclusão e exclusão dos estudos e avaliação dos mesmos (Mendes et al, 2008).

Para a elaboração da questão norteadora, utilizou-se a estratégia, para revisões de literatura, Population, Intervention, Comparation, Outcome (PICO) (Santos et al, 2007). Para este estudo foi estabelecido P: gestantes com o estresse emocional 
agravado, Intervention: o uso de plataformas digitais para a assistência destas pacientes, C: não utilizado neste estudo, O: a atuação da Enfermagem na adaptação da assistência. Neste seguimento, a concepção da questão norteadora foi: "Como a equipe de Enfermagem desenvolve as ações de cuidado para tentar diminuir o estresse emocional nas gestantes no decurso do ciclo gravídico durante a pandemia?".

\subsection{Coleta de dados}

O levantamento das publicações foi realizado em setembro de 2021, nas bases de dados: Bases de Dados de Enfermagem (BDENF), Literatura Latino-Americana e do Caribe em Ciências da Saúde (LILACS) e Scientific Electronic Library Online (SCIELO) na Biblioteca Virtual em Saúde (BVS). Os descritores, de acordo com os Descritores em Ciência da Saúde (DeCS) foram: Gestantes; Saúde Mental; COVID-19; Enfermagem Obstétrica e Adaptação, sendo cruzados com os marcadores booleanos "and" e "or".

Os descritores foram combinados originando as buscas descritas no quadro abaixo (Quadro 1):

Quadro 1: Estratégia de busca. Brasília - DF, 2021.

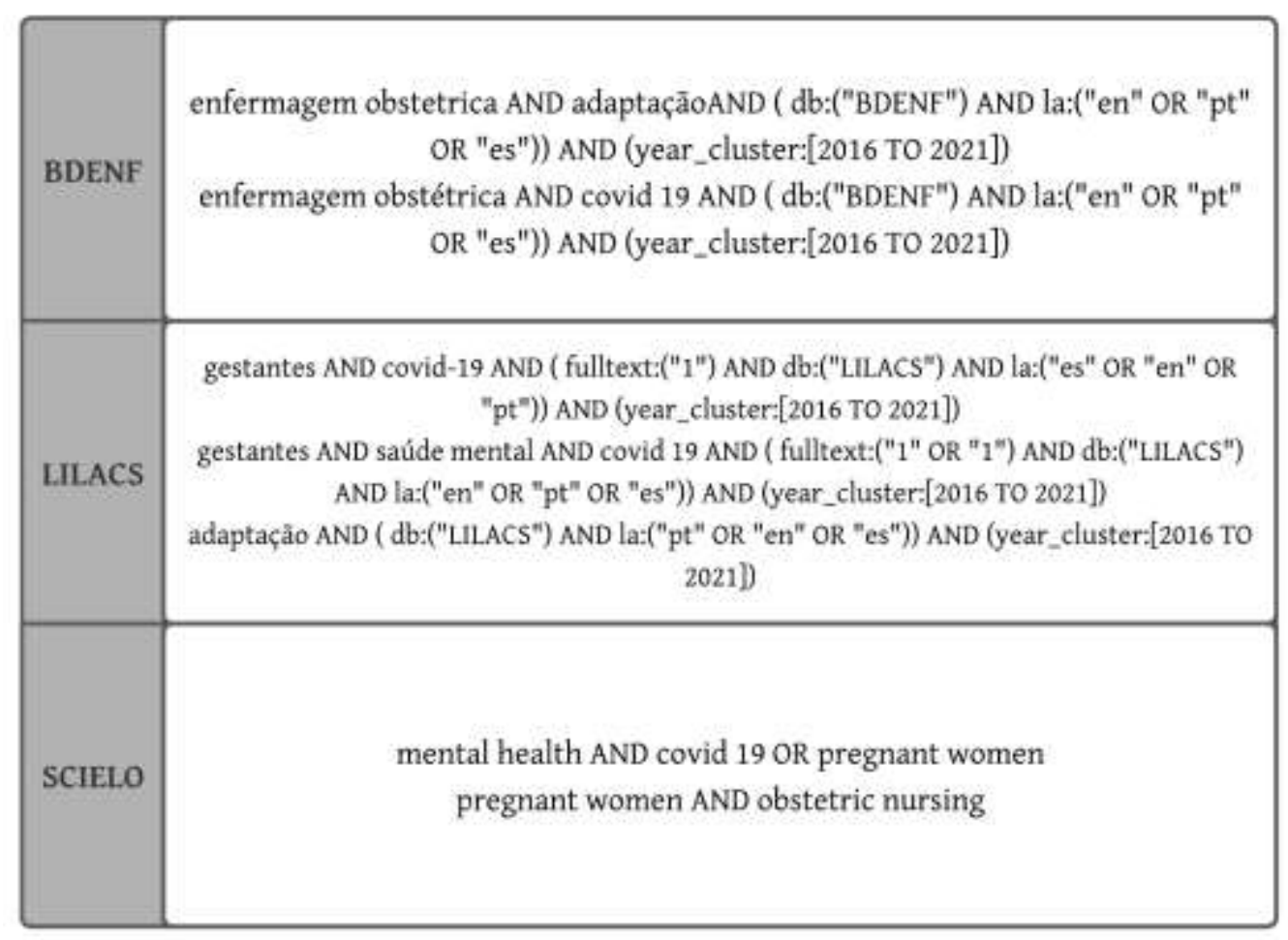

Fonte: Autores (2021).

\subsection{Análise dos dados}

No percurso metodológico foram encontradas 2.741 referências. Os critérios de inclusão foram artigos publicados nos últimos cinco anos nas bases de dados selecionadas de forma completa e livre, nos idiomas português, inglês e espanhol a partir dos descritores selecionados e que correspondiam a seguinte pergunta problema: "Como a equipe de Enfermagem desenvolve as ações de cuidado para tentar diminuir o estresse emocional nas gestantes no decurso do ciclo gravídico durante a pandemia?". Os de exclusão foram artigos incompletos, que não versavam sobre o objetivo do trabalho e duplicatas. Após aplicação dos critérios de inclusão e exclusão foram utilizados dezesseis periódicos, doze sendo nacionais, quatro em inglês e zero em espanhol. 
Figura 1: Fluxograma coleta e análise dos dados. Brasília - DF, 2021.

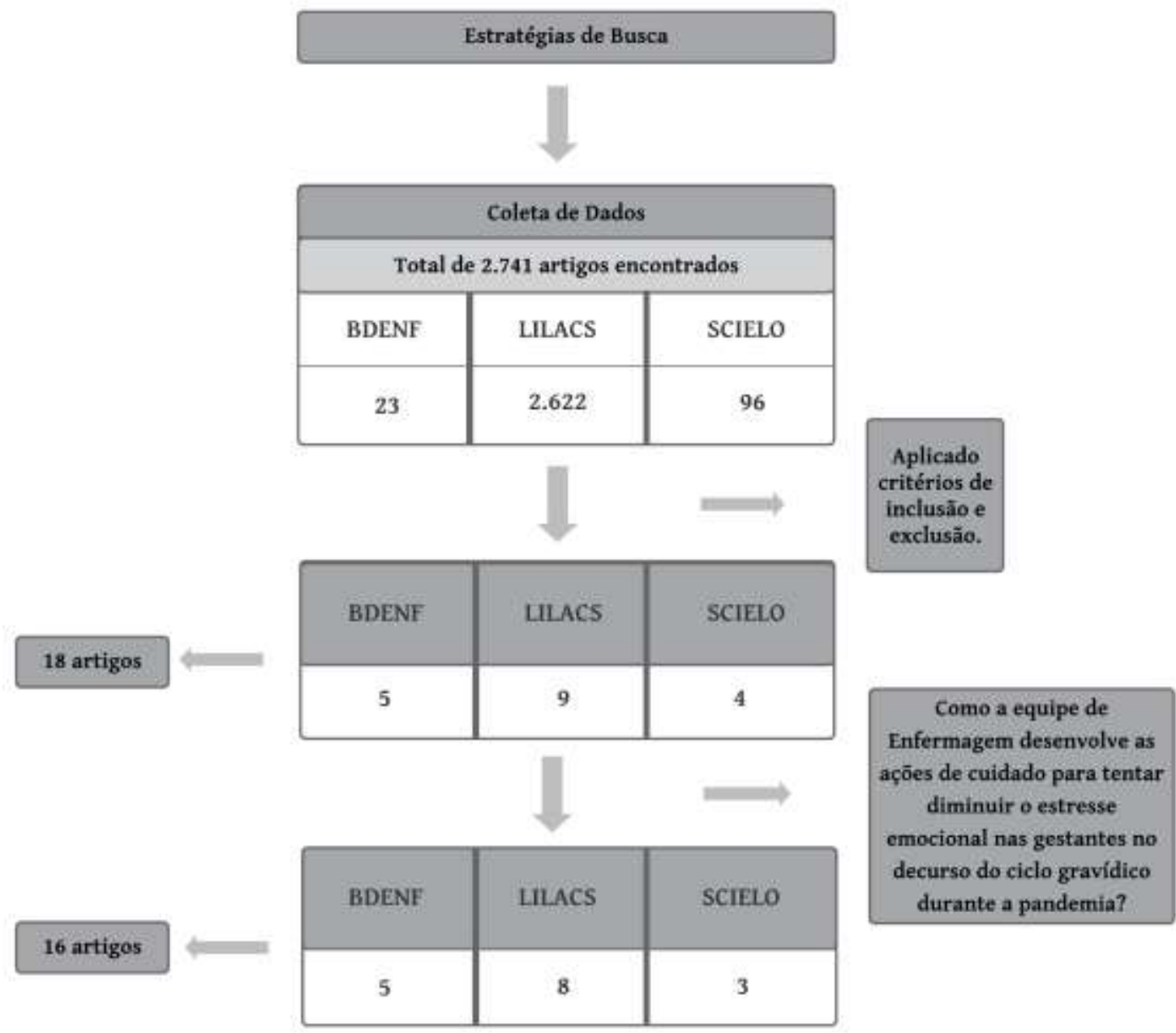

Fonte: Autores (2021)

Os artigos usados nos resultados e discussão foram organizados em um quadro a partir das características título, periódico, ano, método e nível de evidência. Quanto ao nível de evidência, os artigos foram classificados pelo tipo de estudo, por meio do quadro de níveis de evidência científica segundo a classificação de Oxford Centre for Evidence-Based Medicine (CEBM, 2009).

\section{Resultados e Discussão}

Os resultados constituíram o quadro com as descrições das características dos dezesseis artigos utilizados (Quadro 2). 
Research, Society and Development, v. 10, n. 15, e43101522469, 2021

(CC BY 4.0) | ISSN 2525-3409 | DOI: http://dx.doi.org/10.33448/rsd-v10i15.22469

Quadro 2: Quadro com as características dos artigos encontrados. Brasília - DF, 2021.

\begin{tabular}{|c|c|c|c|c|}
\hline Título & Periodico & Ano & Método & $\begin{array}{l}\text { Nivel de } \\
\text { Evidência }\end{array}$ \\
\hline A Prática do Yoga no Pré-Natal & Journals Bahiana & 2020 & Qualitativo & $1 \mathrm{~A}$ \\
\hline $\begin{array}{l}\text { Assistência ao Recém-Nascido na Sala de } \\
\text { Parto durante a Pandemia de Covid-19 }\end{array}$ & $\begin{array}{l}\text { Acta Paulista de } \\
\text { Enfermagem }\end{array}$ & 2021 & Qualitativo & $2 A$ \\
\hline $\begin{array}{c}\text { Best Practices In Newborn Care In Covid-19 } \\
\text { Times }\end{array}$ & $\begin{array}{l}\text { Portal de Revistas de } \\
\text { Enfermagem }\end{array}$ & 2020 & Qualitativo & $2 A$ \\
\hline $\begin{array}{l}\text { Clinical Features and Maternal-fetal } \\
\text { Results of Pregnant Women in COVID-19 } \\
\text { Times }\end{array}$ & $\begin{array}{l}\text { Revista Brasileira de } \\
\text { Ginecologia e Obsterícia }\end{array}$ & 2021 & Qualitativo & $2 \mathrm{~A}$ \\
\hline $\begin{array}{l}\text { Consultoria em Amamentação Durante a } \\
\text { Pandemia CoVID-19: relato de experiência }\end{array}$ & Escola Anna Nery & 2020 & Qualitativo & 4 \\
\hline $\begin{array}{l}\text { Contentamento de Puérperas Assistidas } \\
\text { Por Enfermeiros Obstetras }\end{array}$ & $\begin{array}{c}\text { Revista de Enfermagem } \\
\text { UFPE }\end{array}$ & 2018 & Quantitativo & $1 B$ \\
\hline $\begin{array}{l}\text { COVID-19 Fear Scale - Validation and } \\
\text { Adaptation for the Perinatal Period }\end{array}$ & $\begin{array}{l}\text { Journal of Human } \\
\text { Growth and } \\
\text { Development }\end{array}$ & 2021 & Quantitativo & $2 B$ \\
\hline $\begin{array}{l}\text { Direitos Humanos das Mulheres no Parto } \\
\text { Frente à Pandemia de Covid-19: O Quefazer } \\
\text { da Enfermagem Obstétrica }\end{array}$ & $\begin{array}{l}\text { Revista Cogitare } \\
\text { Enfermagem }\end{array}$ & 2020 & Qualitativo & $2 \mathrm{~A}$ \\
\hline $\begin{array}{l}\text { Enfermagem Obstétrica e Sua Força de } \\
\text { Trabalho em Tempos de Covid-19: relato de } \\
\text { experiência das regiōes do Brasil }\end{array}$ & $\begin{array}{l}\text { Revista Oficial do Conselho } \\
\text { Federal de Enfermagem }\end{array}$ & 2020 & Qualitativo & 4 \\
\hline $\begin{array}{l}\text { Gestantes no Contexto da Pandemia da } \\
\text { Covid-19: reflexōes e desafios }\end{array}$ & $\begin{array}{l}\text { Physis: Revista de Saúde } \\
\text { Coletiva }\end{array}$ & 2020 & Qualitativo & $2 \mathrm{C}$ \\
\hline $\begin{array}{l}\text { Impacto Psicossocial do Vírus Covid-19: } \\
\text { emoçōes, preocupações e necessidades numa } \\
\text { amostra portuguesa }\end{array}$ & $\begin{array}{l}\text { Psicologia, Saúde e } \\
\text { Doenças }\end{array}$ & 2020 & Quantitativo & $2 B$ \\
\hline Parenting, Mental Health, and Covid - 19 & $\begin{array}{l}\text { Psicologia: teoria e } \\
\text { prática. }\end{array}$ & 2021 & Qualitativo & $1 \mathrm{~A}$ \\
\hline $\begin{array}{l}\text { Telenfermagem na Covid-19 e saúde } \\
\text { materna: WhatsApp como ferramenta } \\
\text { de apoio }\end{array}$ & $\begin{array}{l}\text { Acta Paulista de } \\
\text { Enfermagem }\end{array}$ & 2021 & Quantitativo & $2 B$ \\
\hline $\begin{array}{c}\text { Teorias de Enfermagem Utilizadas nos } \\
\text { Cuidados a Hipertensos }\end{array}$ & $\begin{array}{l}\text { Revista Oficial do } \\
\text { Conselho Federal de } \\
\text { Enfermagem }\end{array}$ & 2021 & Qualitativo & $1 \mathrm{~A}$ \\
\hline $\begin{array}{c}\text { Transtorno de Adaptação Decorrente do } \\
\text { Parto: avaliação de sinais e sintomas em } \\
\text { puérperas }\end{array}$ & $\begin{array}{l}\text { Revista Eletrônica de } \\
\text { Enfermagem }\end{array}$ & 2019 & Quantitativo & $2 B$ \\
\hline $\begin{array}{c}\text { Violência Obstétrica: a abordagem da } \\
\text { temática na formação de enfermeiros } \\
\text { obstétricos }\end{array}$ & $\begin{array}{l}\text { Acta Paulista de } \\
\text { Enfermagem }\end{array}$ & 2020 & Qualitativo & $2 B$ \\
\hline
\end{tabular}

Fonte: Autores (2021). 


\subsection{Conhecendo e analisando os possíveis estressores emocionais das gestantes}

A descoberta e a passagem pela gestação já são um estressor por si só, pois traz momentos de conflitos internos, angústias e no momento da pandemia trouxe maiores ansiedades e preocupações diante a situação, trazendo o estresse emocional (Vescovi et al, 2021). A responsabilidade que a gravidez traz para a gestante junto com os estressores psicológicos trazidos pela pandemia obrigam a gestante e a puérpera a se adaptarem com desafios maiores junto a equipe de Enfermagem.

A pandemia, inegavelmente, trouxe às gestantes o medo da transmissão vertical do vírus, não poder amamentar como esperado, a possibilidade de não poder ter acompanhante de sua escolha durante o parto e a falta de humanização durante o mesmo somados ao distanciamento social e de súbito a falta de ajuda de outros familiares presencialmente, propiciando a maior probabilidade do desenvolvimento da depressão pós-parto (Estrela et al, 2020).

Até o momento não há comprovação científica de que a transmissão vertical do COVID-19 possa ocorrer (Godoi et al, 2021), mas inopinadamente a transmissão horizontal aconteça caso não haja controle das precauções primárias contra o vírus, principalmente durante a amamentação e se a parturiente é sintomática (Oliveira et al, 2021). De acordo com o relato de experiência de enfermeiras consultoras de amamentação, as lactantes insistiram em oferecer o leite materno para seus recémnascidos e como em qualquer outro momento, algumas mostraram dificuldades para amamentar apresentando e relatando dores, desconfortos, ingurgitamento mamário e diminuição na produção do leite, dessa maneira, as consultoras ainda puderam auxilialas presencialmente, trajando toda a paramentação necessária, quanto nos problemas mamários apresentados, tanto na paramentação das parturientes durante a amamentação (Lima et al, 2020). Portanto, as gestantes podem se tranquilizar pois poderão ter auxílio, apoio e liberdade para amamentar seus filhos.

O medo da falta da humanização durante a gravidez, parto e puerpério é amiudado para algumas gestantes e parturientes. Durante a pandemia este sintoma se tornou ainda mais presente, principalmente pela orientação a evitar a presença do acompanhante. A presença do acompanhante de escolha da gestante é prevista pela Lei no 11.108/2005 (Estrela et al, 2020) e as intervenções médicas sem indicação obstétrica continuam sendo crime, e a decisão da gestante em relação ao seu corpo e ao seu parto ainda deverão ser respeitados (Souza et al, 2020), quanto ao que é preconizado pela Rede Cegonha sobre os cuidados obstétricos (Alves et al, 2020). Algumas mulheres expressam inadaptação ao estar gestante e ao ambiente (Ferreira et al, 2019) em que irão parir e consequentemente, concordam com intervenções desnecessárias apresentadas à fim de retirar-se desta situação (Silva et al, 2020). A priori suas escolhas devem ser totalmente respeitadas, levando em consideração de que a mulher tenha ciência do que está escolhendo, e isto cabe a equipe a deixa-la à par de todos os benefícios e malefícios.

No estudo conduzido pela Associação Americana de Psiquiatria, mostrou que a maioria da população se sente mais ansiosa e preocupada de infectar outro ente querido ao ser infectado (Patrão et al, 2020), sendo assim, já por consequência da pandemia que trouxe consigo o distanciamento social, a gestante perde sua rede de apoio (Souza et al, 2020), então é importante salientar que tudo isso é apenas uma fase e que ela, por enquanto, pode encontrar vários outros meios de estar próxima da família distante para que isso não se torne maior do que já pode ser, e a Enfermagem deve incentiva-la a manter contato com os amigos e familiares de forma virtual e frisar que a equipe também torna-se sua rede de apoio.

\subsection{Adaptando a assistência de enfermagem de acordo com as limitações causadas pela pandemia}

No modelo de Adaptação de Roy, a pessoa se expõe a diversas circunstâncias, influências e ambientes que afetam o desenvolvimento e estimulam a adaptação dos indivíduos (Cavalcante et al, 2021). Um estudo realizado por enfermeiros obstetras em um Centro de Parto Normal concluiu que a assistência ao parto e puerpério pelo enfermeiro obstetra e pela equipe de Enfermagem foi bastante positiva, de acordo com as respostas das parturientes (Ribeiro et al, 2018), enquanto a International Council of Nurses trouxe resultados positivos a partir da telenfermagem (Oliveira et al, 2021). 
A telenfermagem se mostrou presente e eficaz, trazendo resultados positivos da comunicação entre o paciente e a equipe de Enfermagem. Principalmente porque deve-se se adaptar a rotina diária do paciente facilitando a consulta para que o mesmo queira participar, levando em consideração o grupo de pessoas que podem ser prejudicados, como as gestantes de baixa renda, sem conexão à internet, sendo necessário conceder prioridade ao atendimento domiciliar às mesmas. Foi implementado o "Fale com a Parteira Recife- PE", onde 56 enfermeiras obstétricas realizaram e contribuíram nos teleatendimentos por meio do WhatsApp ${ }^{\circledast}$, o mesmo foi muito bem aceito, oferecendo suporte, acolhimento e segurança para as gestantes, e mostrou que as intervenções utilizando a tecnologia foram de grande apoio para as mesmas (Oliveira et al, 2021).

De início, se faz necessário avaliar o medo das gestantes referente ao COVID-19. Para auxiliar, há a The COVID-19 Fear Scale for the Perinatal Period (EMC-19-9), que foi desenvolvida e testada a partir do recrutamento online, onde os critérios de inclusão eram estar gestante, ter mais de 18 anos e ser fluente na língua portuguesa. Por fim, a ferramenta se tornou confiável e válida para avaliar a gravidade do medo do COVID-19 (Barros et al, 2021). E para a equipe, pode ser uma grande aliada juntamente com a telenfermagem, permitindo planejar a prevenção do desenvolvimento de outros distúrbios e tratamento do estresse emocional.

Durante a consulta por meio da telenfermagem a Enfermagem deverá realizar o pré-natal iniciando pela anamnese (Oliveira et al, 2021), coletando antecedentes pessoais, psicológicos, familiares e obstétricos, calcular a idade gestacional em todas as consultas, calcular a data provável do parto para que a gestante possa se programar para o parto e ser orientada de acordo com a fase de sua gestação, para que não seja um fator de maior estresse, avaliar a situação nutricional e emocional, orienta-la a atualizar seu cartão vacinal e programar uma consulta presencial para que possa ser realizado o exame físico completo e administração das vacinas ou reforços ausentes, para que ela possa se sentir mais segura enquanto imunizada, educa-la sobre o aleitamento materno (Lima et al, 2020), sinais de trabalho de parto, puerpério, cuidados com o recém-nascido, sexualidade, alterações físicas e psíquicas para que ela seja capaz de distinguir quais sintomas são fisiológicos e quais são patológicos, incentiva-la a realizar atividade física, como a yoga pré-natal, por exemplo, (Araújo et al, 2020) que reduz o cortisol materno e realizar escuta qualificada, para estabelecer a relação de confiança entre paciente e equipe de Enfermagem para reconhecer o estresse emocional, (Vescovi et al, 2021) podendo utilizar a The COVID-19 Fear Scale como ferramenta de apoio para calcular de forma precisa o medo da gestante, e acolher, empaticamente, esta gestante (Barros et al, 2021). A Enfermagem pode também ser amparada pela equipe multidisciplinar, conjeturando o Pré-Natal Psicológico com acompanhamento de profissionais especializados (Ferreira et al, 2019).

Portanto, a Enfermagem se faz capaz de desenvolver a assistência às gestantes no período pandêmico estabelecendo uma relação de confiança, respeitando e orientando a gestante por meio de seus medos, mostrando que a mesma ainda tem sua rede de apoio, onde ela será resguardada a partir da humanização e assegurada pelas leis previstas constitucionalmente. A Enfermagem desenvolverá a assistência por meio da telenfermagem, compactando o pré-natal nas consultas virtuais e as visitando apenas quando necessário e trajando a paramentação obrigatória, prevendo a segurança da gestante e o menor tempo de contato físico possível à fim de evitar a possibilidade de transmissão da COVID-19. Os profissionais poderão utilizar a Fear Scale for the Perinatal Period para avaliar o medo das gestantes referente ao COVID-19 para que possam, de forma precisa, orientar, acolher e encaminhar a mulher com o estresse emocional agravado no período gravídico.

\section{Considerações Finais}

Diante ao presente estudo, a Enfermagem desenvolverá de forma eficaz a assistência às gestantes com o estresse emocional agravado no decurso do ciclo gravídico durante o período pandêmico a partir da telenfermagem, trazendo novas formas de abordar e calcular o medo, contando com a equipe multidisciplinar como apoio. 
Research, Society and Development, v. 10, n. 15, e43101522469, 2021

(CC BY 4.0) | ISSN 2525-3409 | DOI: http://dx.doi.org/10.33448/rsd-v10i15.22469

Portanto, as gestantes podem se tranquilizar diante de seus medos, pois a equipe de Enfermagem se faz presente e preparada para lidar com as divergências em conjunto com as mesmas. Principalmente porque a assistência intra e extrahospitalar deverá ser a mesma, seguindo todos os protocolos já implementados, com humanização e respeito pelas decisões das gestantes e parturientes.

Ademais, caberá a equipe de Enfermagem fornecer apoio virtualmente e presencialmente quando necessário, portando a paramentação obrigatória, para que os efeitos do estresse emocional sejam rebatidos de forma segura.

\section{Referências}

Alves, V., Souza, K., Carmo, J., Moretto, V., Teixeira, R., Freitas, W., \& Sousa, E. (2020). Enfermagem obstétrica e sua força de trabalho em tempos de Covid19: relato de experiência das regiões do Brasil. Enfermagem em Foco, 11(2.ESP). https://doi.org/10.21675/2357-707X.2020.v11.n2.ESP.3967

Araújo, M. A. N., \& Prado, B. G. L. (2020). A Prática do Yoga no Pré-natal: redução do estresse e outros achados. Revista Psicologia, Diversidade E Saúde, 9(3), 374-387. https://doi.org/10.17267/2317-3394rpds.v9i3.3051

Barros, M. N. dos, Aguiar, M. M., Carvalho, F. Macedo, A., \& Pereira, A. T. (2021). COVID-19 Fear Scale - Validation and adaptation for the perinatal period. Journal of Human Growth and Development, 31(1), 9-17. https://dx.doi.org/10.36311/jhgd.v31.11546

Centre for Evidence-Based Medicine (CEBM). (2009). Oxford Centre for Evidence-Based Medicine: Levels of Evidence. https://www.cebm.ox.ac.uk/resources/levels-of-evidence/oxford-centre-for-evidence-based-medicine-levels-of-evidence-march-2009

Cunha, A., \& Albuquerque, K., (2020). Maternidade em Tempos de COVID-19: Como enfrentar a pandemia quando sou mãe de um bebê menor de seis meses. (LEPIDS/UFRJ) em parceria com o Programa de Residência Multiprofissional em Saúde, da Universidade Federal do Espírito Santo. ISBN: 978-65-00-041385. p. 3-4.

Estrela, F., Silva, K., Cruz, M., \& Gomes, N. (2020) Gestantes no contexto da pandemia da Covid-19: reflexões e desafios. Physis. $30(2)$ : e300215. https://doi.org/10.1590/s0103-73312020300215.

Ferreira, Q. T., Vasconcelos De Lima, L. S., De Lima e Silva, L. X., Ferreira Aquino, D. M., \& Castro, J. F. D. L. (2019). Transtorno de adaptação decorrente do parto: avaliação de sinais e sintomas em puérperas. Revista Eletrônica De Enfermagem, 21. https://doi.org/10.5216/ree.v21.53876

Godoi, A., Bernardes G., Nogueira L., Alpoim, P., \& Pinheiro M. (2021). Clinical Features and Maternal-fetal Results of Pregnant Women in COVID-19 Times. Revista Brasileira de Ginecologia e Obstetrícia, 43(5), 384-394. https://doi.org/10.1055/s-0041-1729145.

Leandro Cavalcante, F., Morais Oliveira, I., Pires Campos, M., Melo de Sousa, F., Sousa Paiva, T., \& Moreira Barros, L. (2021). Teorias de enfermagem utilizadas nos cuidados a hipertensos. Enfermagem em Foco, 12(2). https://doi.org/10.21675/2357-707X.2021.v12.n2.3392

Lima, A., Chaves A., Oliveira M., Lima S., Machado M., \& Oriá M. (2020). Consultoria em amamentação durante a pandemia COVID-19: relato de experiência. Escola Anna, 24, e20200350. https://doi.org/10.1590/2177-9465-EAN-2020-0350.

Mendes, K., Silveira, R., \& Galvão, C. (2008). Revisão integrativa: método de pesquisa para a incorporação de evidências na saúde e na enfermagem. Texto contexto - enferm. 17(4):758-64. https://doi. org/10.1590/S0104-07072008000400018.

Ministério da Saúde. (2020). Coronavírus - COVID19 - Como se Proteger https://coronavirus.saude.gov.br/sobre-a-doenca\#como-se-proteger.

Oliveira, C. E. de S., et al (2021). Assistência ao recém-nascido na sala de parto durante a pandemia de COVID-19. Acta Paulista de Enfermagem,34, eAPE03043. https://dx.doi.org/10.37689/acta-ape/2021ar03043

Oliveira, S. C., et al (2021). Telenfermagem na COVID-19 e saúde materna: WhatsApp® como ferramenta de apoio. Acta Paulista de Enfermagem,34, eAPE02893. https://dx.doi.org/10.37689/acta-ape/2021ao02893

Organização Pan-Americana Da Saúde/Organização Mundial da Saúde. (2020) Atualização Epidemiológica - COVID 19 durante a gestação.

Organização Pan-Americana Da Saúde/Organização Mundial da Saúde. (2021) Folha Informativa - COVID-19 (doença causada pelo novo corona vírus) https://www.paho.org/pt/covid19.

Patrão, I., et al (2020). Impacto psicossocial do virus COVID-19: emoções, preocupações e necessidades numa amostra portuguesa. Psicologia, Saúde \& Doenças, 21(3), 541-557. https://doi.org/10.15309/20psd210301

Ribeiro, J., de Oliveira, K., Lira, J., Chagas, D., Branca, S., Lima, F., \& Galvão, T. (2018). Contentamento de puérperas assistidas por enfermeiros obstetras. Revista de Enfermagem UFPE on line, 12(9), 2269-2275. https://doi.org/10.5205/1981-8963-v12i9a234777p2269-2275-201821

Santos, C., Pimenta, C., \& Nobre, M. (2007). The PICO strategy for the research question construction and evidence search. Rev. Latino-Am. Enfermagem, 15(3):508- 11. https://doi.org/10.1590/S0104- 11692007000300023.

Silva, T., Sousa K., Oliveira A., Amorim, F., \& Almeida, C. (2020). Violência obstétrica: a abordagem da temática na formação de enfermeiros obstétricos. Acta Paulista de Enfermagem, 33, eAPE20190146. https://doi.org/10.37689/acta-ape/2020AO01466. https://doi.org/10.37689/acta-ape/2020AO01466. 
Research, Society and Development, v. 10, n. 15, e43101522469, 2021

(CC BY 4.0) | ISSN 2525-3409 | DOI: http://dx.doi.org/10.33448/rsd-v10i15.22469

Souza, K., Schneck, S., Pena, É., Duarte, E., \& Alves, V. (2020). Direitos humanos das mulheres no parto frente à pandemia de covid-19: o quefazer da enfermagem obstétrica. Cogitare Enfermagem, 25. http://dx.doi.org/10.5380/ce.v25i0.73148

Souto, S., Albuquerque, R., \& Prata, A. (2020). O medo do parto em tempo de pandemia do novo coronavírus. Rev. Bras. Enferm. 73(Suppl 2): e20200551. Epub 13-Nov-2020. https://doi.org/10.1590/0034-7167-2020-0551.

Vescovi, Gabriela, Riter, Helena da S., Azevedo, Elisa C., Pedrotti, Bruna G., \& Frizzo, Giana B. (2021). Parenting, mental health, and Covid-19: a rapid systematic review. Psicologia: teoria e prática, 23(1), 01-28. https://dx.doi.org/10.5935/1980-6906/ePTPC1913554

World Health Organization (WHO). (2020). Coronavirus Disease (COVID-19) Pandemic. https://www.who.int/emergencies/diseases/novel-coronavirus2019. 